Johnson \& Wales University ScholarsArchive@JWU

Health \& Wellness Department Faculty

Publications and Research

College of Health \& Wellness

$10-2018$

\title{
The Internet Addiction Test in a Young Adult U.S. Population
}

S R. Rosenthal

Johnson \& Wales University - Providence, Samantha.Rosenthal@jwu.edu

MA. Clark

Y Cha

M A. Clark

Follow this and additional works at: https://scholarsarchive.jwu.edu/health_fac

Part of the Medicine and Health Sciences Commons

\section{Repository Citation}

Rosenthal, S R.; Clark, M A.; Cha, Y; and Clark, M A., "The Internet Addiction Test in a Young Adult U.S. Population" (2018). Health \& Wellness Department Faculty Publications and Research. 5.

https://scholarsarchive.jwu.edu/health_fac/5 


\title{
The Internet Addiction Test in a Young Adult U.S. Population
}

\author{
Samantha R. Rosenthal, PhD, MPH, ${ }^{1,2}$ Yoojin Cha, MSc, and Melissa A. Clark, $\mathrm{PhD}^{2,4}$
}

\begin{abstract}
Internet use has increased rapidly over the past 20 years, accompanied by a growing number of individuals whose Internet use has adverse effects on their lives. Yet no study to date has administered the Young's Internet Addiction Test (IAT) in the United States, nor has the reliability been assessed in a U.S. population. Thus, we aimed to: (a) assess the reliability of the instrument and (b) examine sociodemographic characteristics associated with the Internet addiction score. Participants included young adults 21-28 years of age, the third generation of a 50-year longitudinal cohort, the New England Family Study. The mean weighted kappa across all 20 items of the instrument was 0.45 and the median was 0.46 . To examine correlates of the addiction score, we examined age, gender, race/ethnicity, education, partnership status, employment, social support, and depression diagnosis. In the fully adjusted model, those with social support had -3.96 (95\% CI: -6.52 to -1.41 ) lower Internet addiction scores on average compared to those without social support. Also, those with a depression diagnosis had 3.28 (95\% confidence interval [CI]: 1.03-5.84) higher Internet addiction scores on average compared to those without a depression diagnosis. Study findings suggest that Young's IAT had good reliability in a U.S. young adult population. Therefore, this measure can be a useful tool to measure Internet addiction in young adult populations in the United States. Future studies should examine the potential benefits of social support and depression treatment in Internet addiction among young adults in the United States.
\end{abstract}

Keywords: Internet Addiction Test, young adults, United States, reliability

\section{Introduction}

$\mathbf{T}$ HE NUMBER OF people using the Internet since its inception has grown substantially. In 1995, only 1 in 10 people in the United States used the Internet; as of 2015, 84 percent of adults and 95 percent of teenagers in America were online. ${ }^{1}$ This increase has been accompanied by a concerning growth in the number of individuals whose Internet use has adverse effects, such as poor diet, sleeping problems, and increased risk of depression, in their lives. ${ }^{2-5}$ Although no consensus has been achieved in defining Internet addiction, Block characterized Internet addiction with the following four components: (a) excessive use, (b) withdrawal symptoms, (c) low tolerance, and (d) negative repercussions. ${ }^{6}$ The prevalence of Internet addiction varies among populations, with reports as high as eight percent of adolescents in South Korea $^{7}$ to two percent of Norwegian youth. ${ }^{8}$

While countries like South Korea have already implemented nationwide policies to curb this problem, ${ }^{7}$ Internet addiction is still not recognized in the Diagnostic and Statistical Manual of Mental Disorders. Young compared In- ternet addiction to an impulse control disorder (e.g., similar to gambling) that can cause people's lives to become increasingly dependent on the use of Internet, and described the various services that employers, educators, and other institutions can offer to alleviate Internet addiction. Part of Young's research also included the development of the Internet Addiction Test (IAT), a 20-item measure that attempts to establish whether a respondent suffers from Internet addiction. ${ }^{2}$ Young's IAT was the first test scale to be developed to measure the level of Internet addiction, followed by the Internet-Related Problem Scale (IRPS). ${ }^{9}$

Validation studies such as Khazaal et al. found that IAT scores in a sample of 246 French adults were highly correlated with frequency of Internet use $(r=0.40) .{ }^{10}$ Similarly, the IAT has been shown to correlate with self-diagnosed Internet addiction and the IRPS $(r=0.90) .{ }^{9}$ The IAT also has moderate to high internal consistency based on a study of 86 men and women recruited broadly from the Internet. ${ }^{11}$ However, no study to date has administered the IAT in a young adult U.S. sample or examined the test-retest reliability of the IAT in a U.S. sample. Thus, we aimed to (a) assess the test-retest

\footnotetext{
${ }^{1}$ Department of Health Science, College of Health \& Wellness, Johnson \& Wales University, Providence, Rhode Island. Departments of ${ }^{2}$ Epidemiology and ${ }^{3}$ Behavioral and Social Sciences, Brown School of Public Health, Providence, Rhode Island. ${ }^{4}$ Department of Quantitative Health Sciences, University of Massachusetts Medical School, Worcester, Massachusetts.
} 
reliability of the IAT in a young adult U.S. sample and (b) explore the sociodemographic characteristics correlated with a higher or lower overall IAT score among U.S. young adults. The results of this study will verify the reliability of IAT in U.S. population, therefore providing a reference for future U.S. Internet addiction studies to screen for Internet addiction and design interventions accordingly.

\section{Methods}

\section{Sample and data collection}

The sample under study was the third generation of a 50year longitudinal cohort, the New England Family Study (NEFS). The NEFS is an intergenerational family cohort study established to follow up the adult offspring born to women enrolled during pregnancy as part of the United States National Collaborative Perinatal Project from 1959 to 1966. The third-generation cohort consists of 564 participants who were first enrolled as adolescents in 2004.

In 2013, these third-generation young adults were relocated through previously ascertained contact information, public location services, and Facebook searches. Once located, participants were contacted either by telephone or Facebook message and asked to participate. After completing the initial survey, a random subset of participants was then asked to complete a followup survey 2-6 weeks later. Both surveys were web-based and administered using DatStat Illume 5.1 (DatStat, Inc., Seattle, WA). All study procedures were approved by the Brown University Institutional Review Board.

\section{Measures}

The IAT consists of 20 questions, all measured on a 5point Likert scale. The questions are scored from 1 to 5 , with a score of 1 for the answer "rarely" and 5 for the answer "always." Summative scores ranging from 20 to 49 are considered "average" online users. Scores ranging from 50 to 79 are considered to be Internet users experiencing occasional to frequent problems due to the Internet. Scores ranging from 80 to 100 are considered to be users suffering from significant problems due to their Internet usage. ${ }^{2}$ The factors measured by the IAT are "Withdrawal and Social Problems," "Time Management and Performance," and "Reality Substitute", (Table 1). ${ }^{12}$

All sociodemographic variables were self-reported. Age was assessed in years as a continuous variable; race/ethnicity was dichotomized as white, non-Hispanic or not. Education was dichotomized as college graduate or more versus not completed college or less; both technical college graduates and 4-year college graduates were considered college graduates. Employment status was also collapsed into a binary variable as employed versus unemployed; both part time and full time workers were considered employed. Marital status was categorized as partnered-those who reported being married or a member of an unmarried couple, or not partnered-those who reported being divorced, widowed, separated, or never married.

Social support was defined by responses to the question, "How often do you get the social and emotional support you need?" All those responding "always" or "usually" were considered to receive adequate social support, whereas those responding "sometimes," "rarely," or "never" were con- sidered to not receive adequate social support. Depression diagnosis was defined as an affirmative response to the question, "Has a doctor or other healthcare provider ever told you that you have a disorder (including depression, major depression, dysthymia, or minor depression)? Social support and depression were included as covariates because the literature suggests they are important constructs relevant to addiction. ${ }^{13}$

\section{Data analysis}

There were 117 participants who comprised the reliability sample, having fully completed all IAT questions in both the initial and followup surveys. The full sample, all those completing the initial survey, included 264 participants. $\chi^{2}$ tests for categorical variables and two-sample $t$ tests were used to examine the difference between the full and reliability samples. Reliability of baseline and followup items was assessed by weighted kappa statistics, which were calculated for every item of the IAT. ${ }^{14}$ The following criteria of strength of agreement were used to interpret the value of weighted kappa: $<0.20$ (slight), $0.21-0.40$ (fair), $0.41-0.60$ (moderate), 0.61-0.80 (good), and 0.81-1.00 (very good). The product-moment correlation was used to assess the reliability of the overall IAT summary score. We then used bivariate and multivariable linear regression among the full sample who completed all IAT questions in the initial survey $(n=264)$ to investigate the association between IAT score and sociodemographic characteristics, as well as social support and depression. Bivariate and multivariable analyses were conducted using linear regression to examine the relationship between Internet addiction scores and demographic characteristics, such as age, gender, race/ethnicity, level of education, employment status, partnership status, presence of social support, and depression diagnosis. All data analyses were conducted using STATA (College Station, TX; 2015).

\section{Results}

Descriptive analyses were conducted to tabulate demographic information for the full sample as well as the reliability sample (Table 2). The mean age of the full sample was 25.0 and age ranged from 21 to 28 years. The full sample was predominantly female (59.5 percent), white, nonHispanic (90.1 percent), had a college degree or more (59.5 percent), and had adequate social support (77.3 percent). A minority of the full sample was partnered (40.5 percent), unemployed (17.4 percent), and ever had a depression diagnosis (22.4 percent). There were no significant differences between characteristics of the full sample and the reliability sample using a threshold of $p<0.05$.

Test-retest reliability analyses showed the mean weighted kappa across all 20 items of the IAT was 0.45 and the median weighted kappa was 0.46 (Table 3). Questions 5, 6, 8, 18, and 20 all had fair agreement (kappa value $0.21-0.40$ ). Questions $1,2,3,4,7,9-17$, and 19 all had moderate agreement (kappa values $0.41-0.60)$. The total IAT score values ranged from 20 to 69 ; only 12 respondents had scores greater than or equal to 50 , indicative of frequent life problems caused by Internet use.

No significant relationships were found between the scores and demographic characteristics used. Both social support 
Table 1. Questions from the Internet Addiction Test Organized by Factor

\begin{tabular}{|c|c|c|c|}
\hline $\begin{array}{l}\text { Factor 1: Time management } \\
\text { and performance }\end{array}$ & $\begin{array}{c}\text { Factor 2: Withdrawal and } \\
\text { social problems }\end{array}$ & Factor 3: Reality substitute & Other \\
\hline $\begin{array}{l}\text { Q1. How often do you find } \\
\text { that you stay online longer } \\
\text { than you intended? }\end{array}$ & $\begin{array}{l}\text { Q3. How often do you prefer } \\
\text { the excitement of the In- } \\
\text { ternet to intimacy/relation- } \\
\text { ships with your partner/ } \\
\text { friends? }\end{array}$ & $\begin{array}{l}\text { Q10. How often do you } \\
\text { block out disturbing } \\
\text { thoughts about your life } \\
\text { with soothing thoughts of } \\
\text { the Internet? }\end{array}$ & $\begin{array}{l}\text { Q7. How often do you } \\
\text { check your e-mail be- } \\
\text { fore something else that } \\
\text { you need to do? }\end{array}$ \\
\hline $\begin{array}{l}\text { Q2. How often do you neglect } \\
\text { household chores to spend } \\
\text { more time online? }\end{array}$ & $\begin{array}{l}\text { Q4. How often do you form } \\
\text { new relationships with fel- } \\
\text { low online users? }\end{array}$ & $\begin{array}{l}\text { Q12. How often do you fear } \\
\text { that life without the In- } \\
\text { ternet would be boring, } \\
\text { empty, and joyless? }\end{array}$ & $\begin{array}{l}\text { Q11. How often do you } \\
\text { find yourself anticipat- } \\
\text { ing when you will go } \\
\text { online again? }\end{array}$ \\
\hline $\begin{array}{l}\text { Q6. How often does your } \\
\text { grades or school work suf- } \\
\text { fer because of the amount } \\
\text { of time you spend online? }\end{array}$ & $\begin{array}{l}\text { Q5. How often do others in } \\
\text { your life complain to you } \\
\text { about the amount of time } \\
\text { you spend online? }\end{array}$ & $\begin{array}{l}\text { Q14. How often do you lose } \\
\text { sleep due to late-night } \\
\text { logins? }\end{array}$ & \\
\hline $\begin{array}{l}\text { Q8. How often does your job } \\
\text { performance or productiv- } \\
\text { ity suffer because of the } \\
\text { Internet? }\end{array}$ & $\begin{array}{l}\text { Q9. How often do you be- } \\
\text { come defensive or secretive } \\
\text { when anyone asks you } \\
\text { what you do online? }\end{array}$ & & \\
\hline $\begin{array}{l}\text { Q16. How often do you find } \\
\text { yourself saying "just a few } \\
\text { more minutes" when } \\
\text { online? }\end{array}$ & $\begin{array}{l}\text { Q13. How often do you snap, } \\
\text { yell, or act annoyed if } \\
\text { someone bothers you while } \\
\text { you are online? }\end{array}$ & & \\
\hline \multirow[t]{4}{*}{$\begin{array}{l}\text { Q17. How often do you try to } \\
\text { cut down the amount of } \\
\text { time you spend online and } \\
\text { fail? }\end{array}$} & $\begin{array}{l}\text { Q15. How often do you feel } \\
\text { preoccupied with the Inter- } \\
\text { net when offline, or fanta- } \\
\text { size about being online? }\end{array}$ & & \\
\hline & $\begin{array}{l}\text { Q18. How often do you try to } \\
\text { hide how long you have } \\
\text { been online? }\end{array}$ & & \\
\hline & $\begin{array}{l}\text { Q19. How often do you } \\
\text { choose to spend more time } \\
\text { online over going out with } \\
\text { others? }\end{array}$ & & \\
\hline & $\begin{array}{l}\text { Q20. How often do you feel } \\
\text { depressed, moody, or ner- } \\
\text { vous when you are offline, } \\
\text { which goes away once you } \\
\text { are back online? }\end{array}$ & & \\
\hline
\end{tabular}

and prior depression diagnosis were found to have significant bivariate and multivariable relationships with IAT score. In the bivariate analyses, those who reported having social support had -4.02 (95\% confidence interval [CI]: -6.35 to -1.69) lower IAT scores on average compared to those without social support (Table 4). This significant relationship persisted after adjusting for demographic characteristics and depression diagnosis $(-3.96,95 \% \mathrm{CI}$ : -6.52 to -1.41$)$. In bivariate analyses, those who ever received a depression diagnosis had 3.56 (95\% CI: 1.11-6.02) higher IAT scores on average compared to those with no depression diagnosis, which persisted after adjustment (3.28, 95\% CI: 1.03-5.84).

\section{Discussion}

The purpose of this study was to assess the reliability of IAT scores in a young adult U.S. sample and examine associations between IAT scores and demographic and psychosocial characteristics. There was a strong test-retest reliability between IAT summary scores $(r=0.85)$ and the 20 items in IAT with fair to moderate agreement. Based on the results, IAT is a reliable measure in a young adult U.S. population. Variation in IAT scores was not explained by considered age, gender, race/ethnicity, educational attainment, partnership status, or employment. However, social support and depression diagnosis were found to have significant independent associations with IAT scores.

Internet addiction is becoming a global phenomenon and recognized as a potential threat to health in countries where Internet use is prevalent. ${ }^{15-19}$ It has started a debate among mental health experts as to whether Internet addiction should be considered a psychiatric disorder. Because Internet use is deeply embedded in people's daily lives, Young warned of adverse outcomes due to Internet addiction in three major places: households, schools, and work places. ${ }^{2,18}$ Yet, in this sample, there were no young adults who met the definition of Internet addiction in this study, with only 12 respondents reporting IAT scores greater than or equal to 50. A possible 
TABle 2. Sociodemographic and Psychosocial Characteristics of the Full Sample AND THE Reliability SAMPLE

\begin{tabular}{lcr}
\hline & & $\begin{array}{c}\text { Reliability } \\
\text { sample } \\
(\mathrm{N}=117), \\
\mathrm{n}(\%)\end{array}$ \\
\hline Age, years, mean $(S D)$ & $25.0(0.12)$ & $25.1(0.18)$ \\
Female & $157(59.5)$ & $70(59.8)$ \\
White, non-Hispanic & $237(90.1)$ & $106(90.6)$ \\
College graduate or more & $157(59.5)$ & $74(63.3)$ \\
Partnered & $107(40.5)$ & $54(46.2)$ \\
Unemployed & $46(17.4)$ & $22(18.8)$ \\
Social support & $204(77.3)$ & $86(78.9)$ \\
Depression diagnosis & $57(22.4)$ & $26(24.5)$ \\
\hline
\end{tabular}

$S D$, standard deviation. explanation for this result is that Internet addiction may be more prevalent in younger age groups than the sample age group in this study. ${ }^{11}$ A study in Turkey reported higher Internet addiction prevalence among those younger than 19 years of age than those younger than 30 years of age. ${ }^{20}$ Another potential explanation may be that the true prevalence of Internet addiction in the U.S. population is very low and not detectable in a small sample of 264. Finally, the lack of Internet addiction in this sample may be due to the fact that the sample is predominantly white, non-Hispanic, female, and has a college degree or more. Further research using a population-based sample is needed to assess the true prevalence of Internet addiction in the United States.

Results suggest that participants with a history of depression tended to have higher IAT scores. This aligns with studies in other countries that examined the relationship between psychological disorders and Internet addiction. ${ }^{21-24}$ Internet

Table 3. Test-Retest Reliability of Young's Internet Addiction Test, $N=117$

\begin{tabular}{|c|c|c|}
\hline Question & Agreement (\%) & $\begin{array}{l}\text { Weighted } \\
\text { kappa }\end{array}$ \\
\hline Q1. How often do you find that you stay online longer than you intended? & 84.13 & 0.49 \\
\hline Q2. How often do you neglect household chores to spend more time online? & 87.39 & 0.49 \\
\hline $\begin{array}{l}\text { Q3. How often do you prefer the excitement of the Internet to intimacy/relationships } \\
\text { with your partner/friends? }\end{array}$ & 92.17 & 0.47 \\
\hline Q4. How often do you form new relationships with fellow online users? & 93.33 & 0.57 \\
\hline $\begin{array}{l}\text { Q5. How often do others in your life complain to you about the amount of time you } \\
\text { spend online? }\end{array}$ & 90.43 & 0.38 \\
\hline $\begin{array}{l}\text { Q6. How often does your grades or school work suffer because of the amount of time } \\
\text { you spend online? }\end{array}$ & 92.11 & 0.39 \\
\hline Q7. How often do you check your e-mail before something else that you need to do? & 84.51 & 0.46 \\
\hline $\begin{array}{l}\text { Q8. How often does your job performance or productivity suffer because of the } \\
\text { Internet? }\end{array}$ & 90.13 & 0.27 \\
\hline $\begin{array}{l}\text { Q9. How often do you become defensive or secretive when anyone asks you what } \\
\text { you do online? }\end{array}$ & 93.81 & 0.41 \\
\hline $\begin{array}{l}\text { Q10. How often do you block out disturbing thoughts about your life with soothing } \\
\text { thoughts of the Internet? }\end{array}$ & 94.69 & 0.51 \\
\hline Q11. How often do you find yourself anticipating when you will go online again? & 93.04 & 0.58 \\
\hline $\begin{array}{l}\text { Q12. How often do you fear that life without the Internet would be boring, empty, } \\
\text { and joyless? }\end{array}$ & 88.70 & 0.43 \\
\hline $\begin{array}{l}\text { Q13. How often do you snap, yell, or act annoyed if someone bothers you while you } \\
\text { are online? }\end{array}$ & 91.74 & 0.43 \\
\hline Q14. How often do you lose sleep due to late-night logins? & 90.00 & 0.45 \\
\hline $\begin{array}{l}\text { Q15. How often do you feel preoccupied with the Internet when offline, or fantasize } \\
\text { about being online }\end{array}$ & 94.49 & 0.42 \\
\hline $\begin{array}{l}\text { Q16. How often do you find yourself saying "just a few more minutes" when } \\
\text { online? }\end{array}$ & 90.43 & 0.60 \\
\hline $\begin{array}{l}\text { Q17. How often do you try to cut down the amount of time you spend online and } \\
\text { fail? }\end{array}$ & 92.32 & 0.55 \\
\hline Q18. How often do you try to hide how long you have been online? & 96.09 & 0.40 \\
\hline $\begin{array}{l}\text { Q19. How often do you choose to spend more time online over going out with } \\
\text { others? }\end{array}$ & 95.07 & 0.57 \\
\hline $\begin{array}{l}\text { Q20. How often do you feel depressed, moody, or nervous when you are offline, } \\
\text { which goes away once you are back online? }\end{array}$ & 94.74 & 0.21 \\
\hline Total IAT score (product-moment correlation) & & 0.85 \\
\hline
\end{tabular}

The IAT score can range from 20 to 100; each question has response options "rarely," "occasionally," "frequently," "often," and “always." IAT, Internet Addiction Test. 
Table 4. Crude and Adjusted Expected Change in Internet AdDiction Test Score, $N=264$

\begin{tabular}{|c|c|c|}
\hline & $\begin{array}{l}\text { Crude coefficient } \\
\quad(95 \% \text { CI })\end{array}$ & $\begin{array}{l}\text { Adjusted } \\
\text { coefficient } \\
(95 \% \text { CI) }\end{array}$ \\
\hline Age & $-0.36(-0.86$ to 0.14$)$ & $-0.49(-1.02$ to 0.03$)$ \\
\hline Female & $-0.26(-2.31$ to 1.79$)$ & $-0.88(-2.99$ to 1.23$)$ \\
\hline $\begin{array}{l}\text { White, } \\
\text { non-Hispanic }\end{array}$ & $-0.24(-3.64$ to 3.16$)$ & $0.55(-3.01$ to 4.10$)$ \\
\hline $\begin{array}{l}\text { College } \\
\text { graduate } \\
\text { or more }\end{array}$ & $-0.25(-2.30$ to 1.80$)$ & $0.58(-1.60$ to 2.75$)$ \\
\hline Partnered & $-0.24(-2.29$ to 1.82$)$ & $0.37(-1.77$ to 2.51$)$ \\
\hline Unemployed & $1.67(-1.03$ to 4.37$)$ & $0.24(-2.60$ to 3.08$)$ \\
\hline Social support & $-4.02(-6.35$ to -1.69$)$ & $-3.96(-6.52$ to -1.41$)$ \\
\hline $\begin{array}{l}\text { Depression } \\
\text { diagnosis }\end{array}$ & $3.56(1.11$ to 6.02$)$ & $3.28(1.03$ to 5.84$)$ \\
\hline
\end{tabular}

Bold font indicates statistically significant associations at $p<0.05$. CI, confidence interval.

addiction has also been correlated with depression. ${ }^{13,21,24}$ Another notable association was found between Internet addiction and social support. Results suggest social support is inversely associated with the Internet addiction score. Those with higher Internet addiction scores also reported less social support. Similarly, a study among Turkish adolescents found that poor perceived social support was related to high Internet addiction levels. ${ }^{25}$ Social support has also been shown to play a significant role in preventing relapse among other addictive behaviors as well as recovering from mental illnesses. ${ }^{26,27}$ Further research is required to confirm whether social support may prevent relapse among Internet addicts.

Limitations to this study include its small sample size which may introduce type II error, thereby reducing power to detect significant associations. Also, the sample is not representative of the U.S. young adult population. For this reason, study findings may have limited generalizability. Due to the cross-sectional nature of the survey for the full sample, covariates such as depression and social support cannot be considered causally related. Future prevalence studies should include larger, more representative samples of the U.S. young adult population. Also, future studies examining predictors or correlates of Internet addiction should include those who selfreport as Internet addicts.

This study found the Young's IAT to have good reliability in a young adult U.S. sample. Therefore, this measure can be a useful tool to measure Internet addiction in young adult populations in the United States. There was a low prevalence of Internet addiction within the sample. Therefore, generalization of the results needs to be made with caution. For the true prevalence of Internet addiction in the United States, a population-based sample should be surveyed. Findings suggest that prior depression and social support should be considered when assessing risk for Internet addiction.

\section{Author Disclosure Statement}

No competing financial interests exist.

\section{References}

1. Perrin A, Duggan M. (2015) Americans' Internet access: 2000-2015. Washington, DC: Pew Research Center.

2. Young KS. Internet addiction a new clinical phenomenon and its consequences. American Behavioral Scientist 2004; 48:402-415.

3. Kim K, Ryu E, Chon MY, et al. Internet addiction in Korean adolescents and its relation to depression and suicidal ideation: a questionnaire survey. International Journal of Nursing Studies 2006; 43:185-192.

4. Kim Y, Park JY, Kim SB, et al. The effects of Internet addiction on the lifestyle and dietary behavior of Korean adolescents. Nutrition Research and Practice 2010; 4:51-57.

5. Whang LS, Lee S, Chang G. Internet over-users' psychological profiles: a behavior sampling analysis on internet addiction. Cyberpsychology \& Behavior 2003; 6:143-150.

6. Block JJ. Issues for DSM-V: Internet addiction. American Journal of Psychiatry 2008; 165:306-307.

7. Heo J, Oh J, Subramanian SV, et al. Addictive Internet use among Korean adolescents: a National Survey. Public Library of Science 2014; 9:1-8.

8. Johansson A, Götestam KG. Internet addiction: characteristics of a questionnaire and prevalence in Norwegian youth (12-18 years). Scandinavian Journal of Psychology 2004; 45:223-229.

9. Widyanto L, Griffiths MD, Brunsden VA. Psychometric comparison of the Internet Addiction Test, the InternetRelated Problem Scale, and self-diagnosis. Cyberpsychology \& Behavior 2011; 14:141-149.

10. Khazaal Y, Billieux J, Thorens G, et al. French validation of the internet addiction test. Cyberpsychology \& Behavior 2008; 11:703-706.

11. Widyanto L, McMurran M. The psychometric properties of the Internet addiction test. Cyberpsychology \& Behavior 2004; 7:443-450.

12. Chang MK, Man Law SP. Factor structure for Young's Internet addiction test: a confirmatory study. Computers in Human Behavior 2008; 24:2597-2619.

13. He F, Zhou Q, Li J, et al. Effect of social support on depression of internet addicts and the mediating role of loneliness. International Journal of Mental Health Systems 2014; 8:34.

14. Cohen J. Weighted kappa: nominal scale agreement provision for scaled disagreement or partial credit. Psychological Bulletin 1968; 70:213.

15. Cao FL, Su LY. Internet addiction among Chinese adolescents: prevalence and psychological features. Child: Care, Health and Development 2007; 33:275-281.

16. Fu KW, Chan W, Wong P, et al. Internet addiction: prevalence, discriminant validity and correlates among adolescents in Hong Kong. The British Journal of Psychiatry 2010; 196:486-492.

17. Ferraro G, Caci B, D'Amico A, et al. Internet addiction disorder: an Italian study. Cyberpsychology \& Behavior 2006; 10:170-175.

18. Young KS. (2014) Reflections from the International Congress on Internet Addiction Disorders-Cultural and Clinical Perspectives. The Center for Internet Addiction. http://netaddiction.com/internet-addiction-disorder (accessed June 4, 2016).

19. Mak KK, Lai CM, Watanabe H, et al. Epidemiology of Internet behaviors and addiction among adolescents in six 
Asian countries. Cyberpsychology \& Behavior 2014; 17: 720-728.

20. Sahin C. An analysis of internet addiction levels of individuals according to various variables. The Turkish Online Journal of Educational Technology 2011; 10:60-66.

21. Yen JY, Ko CH, Yen CF, et al. The comorbid psychiatric symptoms of Internet addiction: attention deficit and hyperactivity disorder (ADHD), depression, social phobia, and hostility. Journal of Adolescent Health 2007; 41:93-98.

22. Yoo HJ, Cho SC, Ha J, et al. Attention deficit hyperactivity symptoms and internet addiction. Psychiatry and Clinical Neurosciences 2004; 58:487-494.

23. Currie SR, Patten SB, Williams JV, et al. Comorbidity of major depression with substance use disorders. The Canadian Journal of Psychiatry 2005; 50:660-666.

24. Briere FN, Rhode P, Seeley JR, et al. Comorbidity between major depression and alcohol use disorder from adolescence to adulthood. Comprehensive Psychiatry 2014; 55: 526-533.

25. Gunuc S, Dogan A. The relationship between Turkish adolescents' internet addiction, their perceived social support and family activities. Computers in Human Behavior 2013; 29:2197-2207.

26. Havassy BE, Hall SM, Wasserman DA. Social support and relapse: commonalities among alcoholics, opiate users, and cigarette smokers. Addictive Behaviors 1991; 16:235-246.

27. Hendryx M, Green CA, Perrin N. Social support, activities, and recovery from serious mental illness: STARS study findings. Journal of Behavioral Health Services and Research 2009; 36:320-329.

Address correspondence to: Dr. Samantha R. Rosenthal Department of Health Science College of Health \& Wellness Johnson \& Wales University 8 Abbott Park Pl Providence, RI 02903

E-mail: samantha.rosenthal@jwu.edu 